\title{
GASTRO-OESOPHAGEAL HAEMORRHAGE IN HEPATIC CIRRHOSIS
}

\author{
BY \\ H. BUTLER \\ From the Department of Anatomy, St. Bartholomew's Hospital Medical College, London
}

(RECEIVED FOR PUBLICATION DECEMBER 10,1951 )

The recent development of portal-caval shunt operations has focused attention upon gastrooesophageal haemorrhage in patients suffering from portal venous obstruction, due to hepatic cirrhosis and other causes. These operations have been made possible by modern advances in vascular surgery which allow the construction of large artificial anastomoses between portal and systemic veins and attempt to prevent haemorrhage by reducing portal venous hypertension (Blakemore, 1948; Linton, Hardy, and Volwiler, 1948). The relevant literature, however, reveals conflicting evidence as to the immediate cause of such bleeding, the degree of portal venous hypertension being apparently but one of the factors involved. Furthermore, the accounts of the structure, size, and extent of the varices concerned are incomplete and often contradictory. Hence the pathological anatomy of the gastro-oesophageal varices and of certain other portal-caval anastomoses have been investigated in three patients suffering from portal venous obstruction due to hepatic cirrhosis, with particular attention to the cause of bleeding. Two of the three patients manifested unusually large, natural, portalcaval anastomoses in the falciform ligament, comparable in size to those constructed in portal-caval shunt operations, yet both these had haematemesis.

Bleeding from gastro-oesophageal varices is one of the cardinal signs of portal venous hypertension, from whatever cause, and according to Frerichs (1861) and Preble (1900) the first case of ruptured oesophageal varices due to hepatic cirrhosis was described by Fauvel in 1858. Earlier, Portal (1803) had noted bleeding from oesophageal varices, but had not associated this with cirrhosis of the liver. Preble (1900) analysed the records of 60 fatal instances of gastro-intestinal haemorrhage occurring in patients suffering from hepatic cirrhosis: in 42 of the 60 the oesophagus had been examined at necropsy and varices were present in 35 (i.e. $85 \%$ ). In 19 of these 42 cases the source of bleeding was noted: in 16 it was ruptured oesophageal varices, in the remainder, ruptured gastric varices. In six of the 42 cases examined at necropsy no varices were found, the gastro-intestinal mucosa being said to be intact. The anastomotic veins were found in the submucosa and upon the outer surface of the lower two-thirds of the oesophagus and, in some instances, in the mucosa of the cardiac end of the stomach. The submucosal veins were varicose but not, apparently, those upon the outer surface of the oesophagus. Preble suggested that the lower oesophageal and cardiac submucosal veins became varicose because of their proximity to the site of portal venous obstruction, the poor support afforded to their walls by the submucosa, and the aspiratory effect of respiration. Ulcers and erosions of the gastric and oesophageal mucosa occurred in 12 out of the 42 specimens examined at necropsy, and Preble suggested that this was due to the mechanical action of food particles and was a direct cause of bleeding.

McIndoe (1928) reviewed the problem and found that $50 \%$ of deaths in portal cirrhosis were due to vascular - lesions. He quoted Harris's excellent classification of the sites of the collateral circulation in portal venous obstruction: $(a)$ at the cardia and at the anus where the distinctive absorbing and protective epithelia of the gut establish contact, the sites of varices; $(b)$ at the site of the obliterated embryonic circulation in the falciform ligament; (c) at those places in the abdomen where the gut and its appendages become retroperitoneal during development or become adherent to the abdominal wall pathologically (e.g. the veins of Retzius, the accessory portal veins of Sappey, or the new connexions formed as a result of the Talma-Morrison operation).

McIndoe stated that all cases of portal venous obstruction with gastro-intestinal haemorrhage show well developed oesophageal varices. Though varices are said to be sometimes absent he believed that they could always be found if looked for, since such dilated veins collapse readily after death and 
become invisible under the thick oesophageal epithelium. The point of rupture is usually insignificant, but can easily be found upon injection of the veins. The varices, both submucosal and perioesophageal, occur in the lower quarter of the oesophagus close to the cardia and are connected by vessels perforating the muscular gullet wall. The submucosal varices are divisible into a superficial set lying in longitudinal rows along the oesophagus and fading into a deeper set. (McIndoe gave no criterion for this subdivision of the submucosal varices.) Injection of the varices raises the mucosa into longitudinal ridges which are especially susceptible to trauma with consequent erosion and ulceration. The main source of blood in the varices is the left gastric vein within which the normal direction of blood flow is reversed.

Kegaries (1934) demonstrated the existence of many small longitudinal anastomotic veins in the cardiac submucosa in the normal subject, disposed both superficially and deep to the muscularis mucosae. He was impressed by the small size of these veins and believed that they offered such great resistance to the portal venous blood that they caused the formation of varices in the gastric cardia rather than in the lower oesophagus. In contrast to Preble (1900) and McIndoe (1928) he believed that the submucosal veins were well supported at the cardia, and that their rupture might be due to autodigestion of the poorly nourished oesophageal epithelium by regurgitated gastric juice in addition to trauma by food particles.

Phemister and Humphreys (1947) resected the lower oesophagus and the cardiac end of the stomach in two patients in order to prevent bleeding. Examination of their specimens showed numerous dilated veins under the epithelium of both stomach and oesophagus communicating elaborately with the submucosal veins, together with protrusion of these submucosal veins through the muscularis mucosae. They found no epithelial lesions and suggested the presence of " numerous tiny ruptures through veno-capillary stomata, with the loss of too few epithelial cells to be grossly appreciated." They also pointed out that the gastric varices might constitute a graver danger to the patient than the oesophageal varices.

Walker (1949) noted that the internal or submucosal varices develop first and those outside the oesophagus later; also that submucosal varices may extend into the cervical oesophagus. Blond and Haler (1950) commented that the portal-caval anastomoses utilized by nature in overcoming portal venous obstruction are already present and no new vessels are formed. This accords with observations made in the normal individual (Butlers? 1951) and serves to explain the failure of the Talma을 Morrison operation.

\section{Material AND Methods}

The gastro-oesophageal varices and certain othe\% portal-caval anastomoses were examined after death in three patients who had, during life, suffered from severe hepatic cirrhosis. A summary of their case्E histories is given below.

CASE 1.-A woman, aged 56 years, 10 months before admission developed diarrhoea and was found to have an enlarged liver and spleen and grossly dilated epigastric veins. On January 1, 1950, she was admitted to Addengr brooke's Hospital, Cambridge, in a state of coma ang shortly afterwards vomited $4 \mathrm{oz}$. of blood. There was reason to suspect that her coma was due to an overdos $\overrightarrow{\mathrm{e}}$ of barbiturate. She died in coma on January 3 .

Necropsy revealed multilobular cirrhosis of the live ascites, oesophageal varices, and a large vein, in the free edge of the falciform ligament, connecting ther portal vein to the dilated epigastric veins.

CASE 2.-A man, aged 55 years, was admitted th Addenbrooke's Hospital, Cambridge, on January 19 1950, having vomited a large quantity of blood, said th be three pints.

He had a previous history of haematemesis in Apri⿻ 1949. Investigation then revealed no evidence of pept ulcer, but there was enlargement of the liver and spleem A diagnosis of Banti's disease with bleeding from oesophageal varices was made.

Despite copious blood transfusions he died on January 22. Necropsy revealed Laennec's cirrhosis $\overrightarrow{\mathrm{g}^{\prime}}$ the liver, oesophageal varices, and phlegmonous colitis.

CASE 3.-A man, aged 35 years, had a history repeated small haematemeses for four years before admission. He had jaundice in 1945 . He complained of pain after meals which was relieved by vomiting. He was admitted to Addenbrooke's Hospital, Cambridge, on August 12, 1950, after vomiting two pints of blood. He presented an enlarged spleen and liver and dilateft veins running up over the costal margins. During the next 24 hours he vomited $64 \mathrm{oz}$. of blood and passed two melaenic stools. He recovered after the transfusion of five pints of blood.

On September 1, 1950, he complained of abdominA pain and began to vomit blood, in all about $85 \mathrm{oz}$. One specimen of vomit contained pieces of raw apple. Despite repeated blood transfusions he died September 8.

Necropsy revealed cirrhosis of the liver and enormous oesophageal varices. Further details of this case hav been published elsewhere (Beswick and Butler, 1951). $\frac{O}{\mathbb{D}}$

The stomach and oesophagus were removed in ore piece from Cases 2 and 3, and neoprene latex 601A w injected retrogradely into the left gastric vein. In Case $\frac{d}{d}$ the oesophagus, minus its lowermost two inches, was alone available, and latex was therefore injected intoga superficial oesophageal vein close to the left vagus nerv. 
In each instance the injection pressure was between 40 and $50 \mathrm{~mm}$. $\mathrm{Hg}$, maintained for 30 to 45 minutes. The specimens were then immersed in warm $5 \%$ formalin for one hour before dissection in order to coagulate the latex.

As a control, the normal venous pattern of the oesophagus was investigated in 27 human foetuses, ranging in age from 11 to 40 weeks, and in two fresh specimens of adult stomach and oesophagus (Butler, 1951).

\section{OBSERVATIONS}

The gastric and oesophageal varices found in the above material may be divided into two main topographical groups: (1) internal varices, and (2) external varices.

INTERNAL VARICES.-These occur in the lamina propria and in the submucosa and bulge into the gut lumen. They may be conveniently subdivided further into subepithelial varices and submucosal varices.

Subepithelial Varices.-These are formed by the dilatation of the venous plexuses of the lamina propria, i.e. the subepithelial venous plexus of the oesophagus and the subglandular venous plexus of the stomach, a more detailed account of the normal anatomy of which has been given elsewhere (Butler, 1951). It should be noted that the subepithelial and subglandular venous plexuses are continuous across the cardia, that both plexuses lie in close proximity to the epithelium, and that the normal diameter of their constituent veins is from 50 to $170 \mu$.

In all three present specimens the subepithelial and subglandular veins are markedly dilated and tortuous (Figs. 1 and 2). Most of them are 200 to $300 \mu$ in diameter, but they may attain a diameter of $2.0 \mathrm{~mm}$. as is seen in the juxta-cardiac region of Case 3 (Fig. 1). They have thin $(10-15 \mu)$ walls, consisting of fine white fibrous tissue with, in the larger vessels, a thin (often incomplete) internal elastic lamina. They lie close to the oesophageal epithelium, which itself varies in thickness from 0.14 to $0.55 \mathrm{~mm}$. Normal oesophageal epithelium has a thickness of from 0.13 to $0.24 \mathrm{~mm}$., which suggests that the varices have produced no thinning. The oesophageal, but not the gastric, epithelium stripped more easily in these pathological specimens. Ulceration of the oesophagus was seen in Cases 1 and 3; Case 2 showed multiple gastric erosions extending into the epithelium for more than one half its thickness. The density of the subepithelial and subglandular venous plexuses is such that all the erosions and ulcerations inevitably overlie dilated, thin-walled veins. In all three cases (once in the oesophagus and twice in the stomach) one such vein was the source of the bleeding.

Both the stomach specimens examined show dilatation and tortuosity of the subglandular veins, particularly those of the cardiac end. The varicose oesophageal subepithelial veins are likewise most marked in the juxta-cardiac region, but in Case 2 they are present throughout the entire oesophagus. The venous plexuses of the lamina propria establish numerous connexions with the deeper and larger submucosal veins which lie outside the muscularis mucosae.

Submucosal Varices.-Some of the longitudinal submucosal oesophageal veins are dilated and tortuous, particularly in Cases 2 and 3 (Figs. 1 and 3). Normally the oesophagus exhibits 10 to 15 longitudinal submucosal veins, but, in the pathological specimens, only four to six of these are grossly dilated. They extend for a varying distance along the oesophagus, an extremely large vein in the posterior oesophageal wall of Case 2 extending from the cardia to within $5.0 \mathrm{~cm}$. of the cricoid cartilage, and terminating in a group of smaller varicose submucosal veins traceable up to the cricoid cartilage. This posterior oesophageal vein, when distended with latex, has a diameter of $6.0 \mathrm{~mm}$., contrasting markedly with the $1.0 \mathrm{~mm}$. diameter of the normal longitudinal submucosal oesophageal veins. It lies $0.6 \mathrm{~mm}$. only from the oesophageal lumen and over it the muscularis mucosae is thinned out: histologically its wall is irregularly thickened (varying from 10 to $100 \mu$ ) and its circular muscle coat is incomplete; the internal elastic lamina is complete and is reduplicated in the thickened regions. Similar, but less emphatic, histological changes occur in the remaining submucosal veins.

The longitudinal submucosal oesophageal varices are interconnected by numerous tortuous, dilated, cross-anastomotic channels, while caudally they become continuous with the equally dilated and tortuous submucosal gastric veins. These last, in the cardiac region, attain a diameter of 4.0 to $5.0 \mathrm{~mm}$.

The submucosal gastric and oesophageal veins communicate with the left gastric vein and with the superficial oesophageal veins by means of numerous annectent vessels ramifying through the muscular coats of oesophagus and stomach.

EXTERNAL VARICES.-These are embedded in the outer fibrous coat of the oesophagus close to the oesophageal nerve plexuses. At the cardia they become continuous with the dilated, tortuous, left gastric vein, and its tributaries (Fig. 4). The oesophageal vessels are largest between the bifurcation 


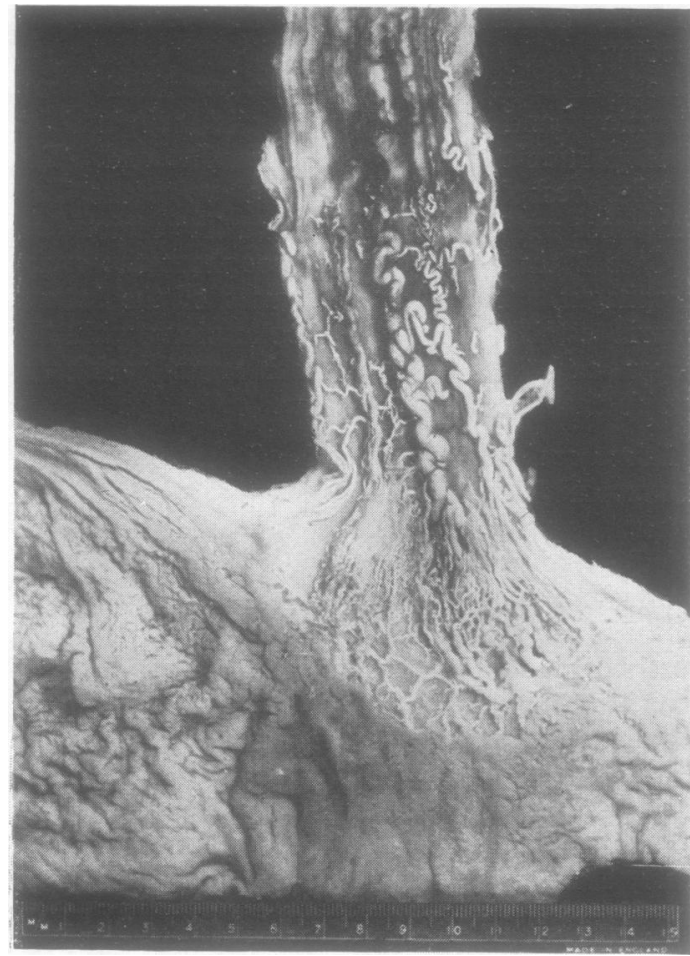

Fig. 1

of the trachea and the cardia and attain a diameter of $3.0 \mathrm{~mm}$. or more. They establish numerous connexions with the submucosal and subepithelial veins by means of dilated, tortuous vessels ramifying throughout its muscular coats (Fig. 5). They drain into the azygos and phrenic veins. The main longitudinal veins running with the vagi form caudally the oesophageal tributaries of the left gastric vein. These veins all lack competent valves, such as are present normally and so disposed as to direct blood from the oesophagus to the azygos and phrenic veins.

Numerous varicose veins occur also within the sheaths of the vagi and their branches (Figs. 5 and 6). In all the three specimens examined, these intraneural varicose vessels are most prominent just proximal to the cardia, where they produce fusiform swellings of the main nerve trunks. (Thus in Case 2, a fusiform swelling, $5.0 \mathrm{~cm}$. long and $1.3 \mathrm{~cm}$. wide, marks the right vagus nerve. Cranial to the swelling the nerve consists of two fas iculi, each $2.0 \mathrm{~mm}$. wide, but caudal to the swelling of a single fasciculus 3.0 $\mathrm{mm}$. wide.) As far as can be ascertained from haematoxylin and eosin stained sections the constituent nerve fibres appear to be normal, although the fasciculi are widely separated by the numerous
Fig. 1.- Inner aspect of the stomach and oesophagus of Case 3. Varices injected with neoprene latex $601 \mathrm{~A}$ and exposed by removing the mucous membrane. (By kind permission of the Editor of the British Medical Journal.)

FIG. 2.-Transverse section through the oesophageal wall of Case 2, showing a very large submucosal vein and the dilated subepithelial veins. Haematoxylin and eosin.

G.V. $=$ gastric varices. $\boldsymbol{M} \cdot \mathbf{M} .=$ muscularis mucosae. Sub.Ep.V. $=\quad$ subepithelial vein. Sub.M.V. = submucosal vein.

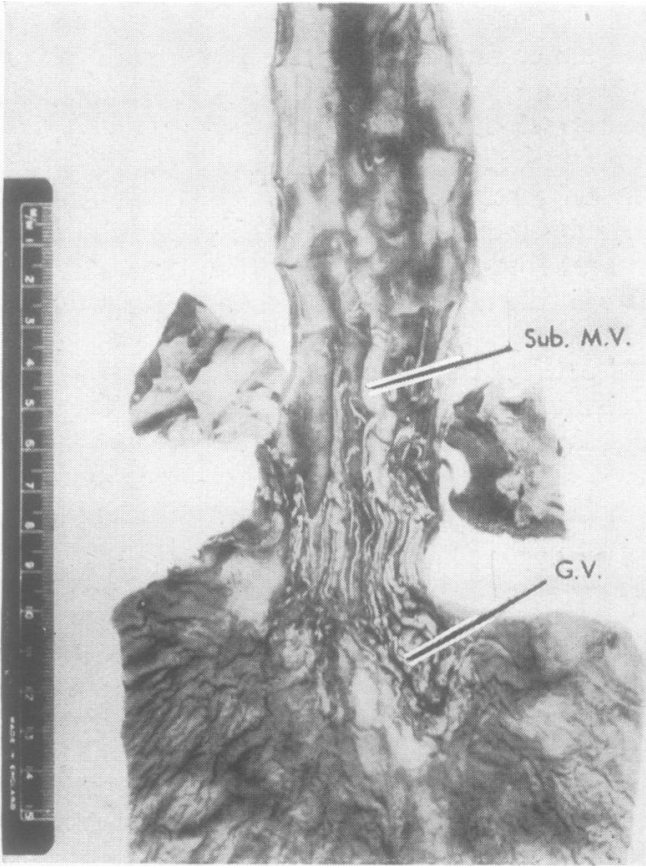

Fig. 3.- Inner aspect of the stomach and oesophagus of Case after injection of the varices with neoprene latex 601A afa exposed by removal of the submucosa, to show the enormous gastric varices and the very large submucosal oesophageal ves seen in section in Fig. 2 . 


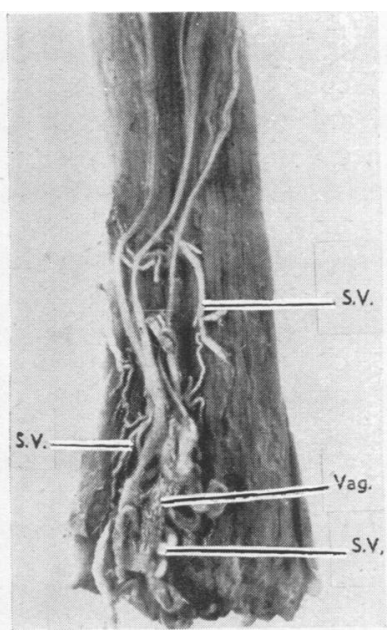

FiG. 4.-Outer aspect of the oesophagus of Case 1 after injection of the varices with neoprene latex $601 \mathrm{~A}$ and showing the superficial varices in and varices in and nerves.

Fig. 6.-Transverse section of the vagus nerve from Case 1 showing the intranhowing varices and neural varices and amount of perineurium. Haematoxylin and eosin.

S.V. = superficial varices. I.M.V. = intramuscular varix. Vag. = vagus nerve.

Fig. 4

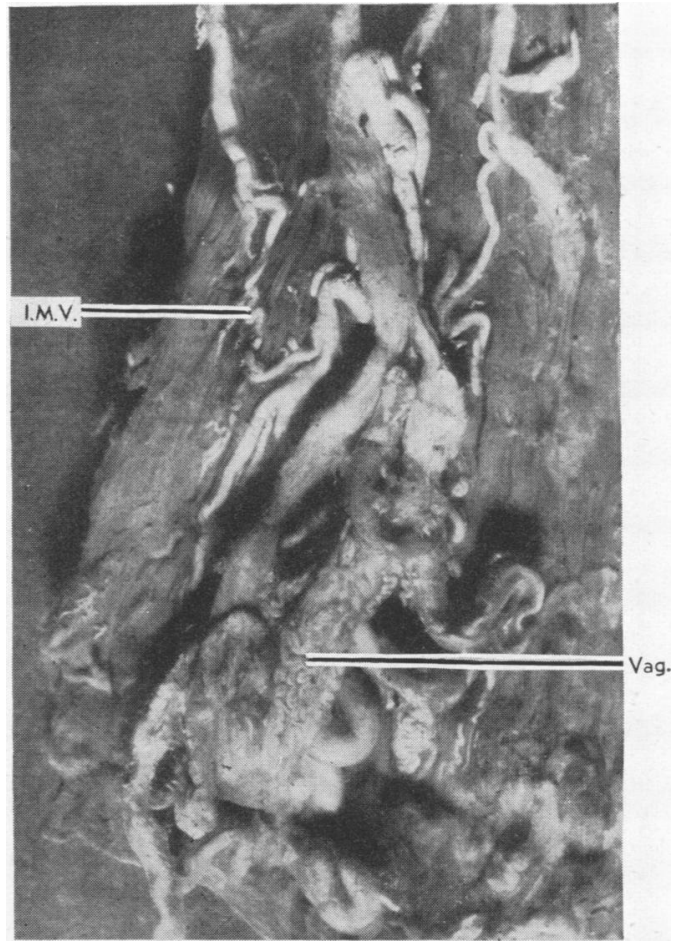

Fig. 5.-Fnlarged view of the lower end of the vagus nerve seen in the previous figure showing the vermiform intraneural varices, also intramuscular varices emerging from the longitudinal muscle coat.

interspersed dilated veins. There appears to be some increase of the perineurium.

In all three cases studied the left gastric vein and its tributaries (particularly the oesophageal and phrenic tributaries) are grossly dilated and tortuous. In Case 2 a large vein, $6.0 \mathrm{~cm}$. long and $4.0 \mathrm{~mm}$. wide, runs along the lesser curvature of the stomach to connect the left gastric vein directly with the right inferior phrenic vein.

Anastomotic Veins in the Falciform LigaMENT.-In all three cases veins in the falciform ligament (particularly large in Cases 1 and 3) connect the left branch of the portal vein to the deep and superficial epigastric veins.

In the first and third specimens the hepatic end of the ligamentum teres is replaced by a large, thickwalled vein, a tributary of the left branch of the portal vein. The distal (umbilical) end of this thickwalled vein is continuous with a thin-walled vein which runs in the free border of the falciform ligament alongside the umbilical end of the ligamentum teres. This thin-walled vessel divides into right and left moieties which pierce the rectus sheath to join the dilated, tortuous, deep epigastric veins (Fig. 7).

Fig. 6 


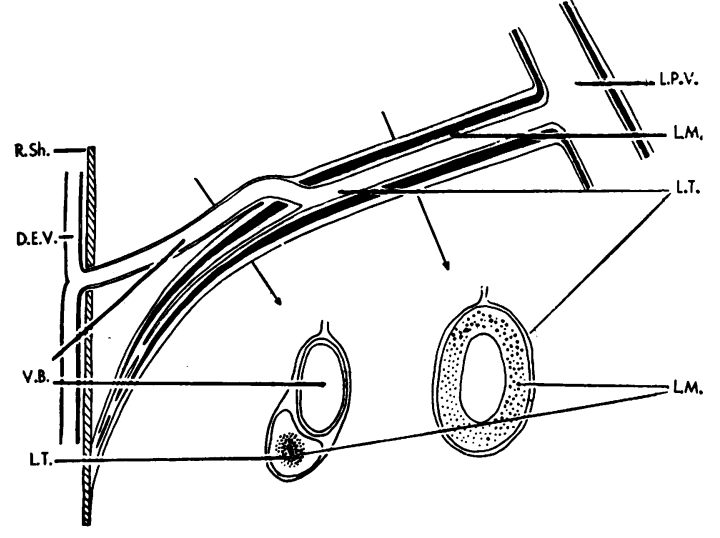

Fig. 7.-Diagram of the anastomotic veins developed in the liga mentum teres and the vein of Burow.

D.E.V. = deep epigastric vein. L.M. = longitudinal muscle of the ligamentum teres. L.P.V. = left branch of the portal vein. L.T. = ligamentum teres. $R . S h .=$ rectus sheath. $V . B .=$ vein of Burow.

which in turn are connected to the similarly dilated and tortuous superficial epigastric veins. By this means the portal venous blood is conveyed to the superior and inferior venae cavae by the subclavian and femoral veins respectively. The lumen of the replacing vein is $12.0 \mathrm{~mm}$. by $3.0 \mathrm{~mm}$. in Case 1, and $6.2 \mathrm{~mm}$. in diameter in Case 3. (These measurements, made on the collapsed and fixed veins, were presumably much greater in life when high-pressure portal venous blood distended the vessels.) The respective thicknesses of the two parts of the vein wall are:

\begin{tabular}{c|c|c}
\hline Case No. & Proximal Portion & Distal Portion \\
\cline { 2 - 3 } 3 & \begin{tabular}{c|c}
$2.0 \mathrm{~mm}$. \\
$1.2 \mathrm{~mm}$.
\end{tabular} & $\begin{array}{l}0.2 \mathrm{~mm} . \\
0.6 \mathrm{~mm} .\end{array}$ \\
\hline
\end{tabular}

These distinctive portions differ markedly in their histology. The thick-walled portion shows a broad media, containing numerous bundles of longitudinal smooth muscle, and is regarded as the modified and dilated proximal end of the intra-abdominal umbilical vein. The thin-walled portion consists almost entirely of white fibrous tissue containing a few scattered circular muscle fibres: it is essentially a grossly dilated vein of Burow. (The veins of Burow (1838) are normally very small, but are constant in the foetus and the adult; they connect the intra-abdominal umbilical vein to the epigastric veins as shown in Fig. 7.) None of the present cases manifests the para-umbilical veins of Sappey (1889), i.e. direct connexions between the portal and epigastric veins.

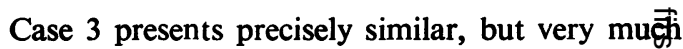
smaller, veins. The vein in the centre of the lig. mentum teres has a slit-like lumen ( 1.0 by $0.25 \mathrm{mn}$ ) and the veins of Burow are less than $1.0 \mathrm{~mm}$. diameter. (A more detailed account of the structu市e and development of these several veins will Be published later.) Here attention is directed solefy to the large size of these vessels in Cases 1 and $\overline{3}$, wherein they form large, direct, adventitious communications between the portal and systenfy venous systems.

\section{Discussion}

The topography and extent of the portal-systemic anastomoses observed in the material examined ${ }_{0}^{\circ} S$ in general agreement with the findings of previotis investigators, but the varices within the vagus nerves appear to have escaped earlier notice. TEe possibility of these intraneural varices interferifg with neural function is a matter for speculation. All the anastomoses naturally uti ized in portal venous obstruction are vessels normally preserw, but become grossly dilated under abnormal physiô. logical strain. The absence of any evidence in $\overline{8}$ cating the formation of new vessels is in keepieg with the failure of the Talma-Morrison operatiof, which depends for its success upon such neovascular formation.

The various anastomoses utilized, both physielogically and operatively, in intrahepatic portal venous obstruction may, on the basis both of their clinical significance and their situation relative the lumen of the gut, be divided into (1) vulnerable anastomoses and (2) protected anastomoses.

VulNerable ÀnAstomoses.-This group cominprises the internal varices, i.e. those of the oesophageal and gastric lamina propria and submucose. They are so termed because their site and their tenuity render them liable to erosion with consequent haemorrhage. This is particularly true of the subepithelial varices (the source of bleeding in af three of the present cases, twice in the stomadh and once in the oesophagus) which extend from the cardia to the cricoid cartilage. Bleeding may occur anywhere within this area, but is most frequent fn $^{2}$ the cardiac end of the stomach and in the lowermost quarter of the oesophagus.

Protected ANASTOMOSES.-This much large group consists of (1) intramuscular varices, (2) superficial varices (including those within the vagal sheaths), (3) the veins of Retzius, (4) the veins the falciform ligament, and (5) surgical anastomoses between the portal and systemic venous systems. These veins do not directly endanger life since, beiro 
more or less removed from the gut lumen, they are not subject to erosion and hence do not bleed. Groups (1) and (2) may, however, indirectly endanger life if there is interference with the direction of flow of their contained blood. In health these veins possess valves directing the blood from the subepithelial and submucosal veins to the superficial veins; in the specimens examined the valves were incompetent because of the extreme venous dilatation. Thus, since the direction of blood flow depends upon the pressure gradient, these veins may either feed blood to, or conduct it from, the internal varices. The direction of their blood-flow in portal venous obstruction is unknown, hence the importance in planning therapeutic measures to remember their potential role as "feeders" of the vulnerable internal varices. Groups (3), (4), and (5) are advantageous in so far as, by draining hightension portal venous blood into the systemic veins, they lessen the risk of bleeding.

The proximate cause of bleeding from the vulnerable internal varices is not always apparent, but the following possibilities should be considered. (1) Trauma to the oesophageal and gastric epithelium by food particles (Preble, 1900; McIndoe 1928; Kegaries, 1934): this clearly seems to have occurred in Case 3, where the fatal bleeding began shortly after the patient had eaten a raw apple. Such a clear-cut example is, however, exceptional and most haemorrhages appear to occur spontaneously. (2) Auto-digestion of the poorly nourished oesophageal epithelium by regurgitated gastric juice (Kegaries, 1934). Experiments on dogs have shown that portal venous obstruction causes an increased susceptibility to gastric erosion (Baronofsky and Wangensteen, 1945). Erosions of the epithelium, both gastric and oesophageal, are common in portal venous obstruction resulting from hepatic cirrhosis. (3) Congenital weakness in the vein walls (Weinberg, 1949). There is no direct evidence in support of this view. (4) The degree of portal venous pressure increases the risk of erosion of the internal varices in so far as it causes them to bulge into the gut lumen. On the contrary, bleeding from oesophageal varices, in the absence of portal venous obstruction, has been occasionally reported (Weinberg, 1949). (5) Varices possessing an internal elastic lamina show areas of re-duplication of this lamina such as is seen in certain arterial degenerations. The cause of such changes is unknown, but it may lie in the profound nutritional changes resulting from hepatic damage.

The most important factor in bleeding from varices appears to be the close proximity of large numbers of extremely thin-walled varices to the gut lumen, thus exposing them to erosion either by trauma or by auto-digestion.

Cases 1 and 3 have very large, naturally formed anastomoses connecting the left branch of the portal vein to the epigastric veins in addition to the more customary anastomoses. The portal-epigastric veins are comparable in size to the surgically produced vascular anastomoses nowadays effected in an attempt to prevent bleeding in portal venous obstruction. Cases similar to those described here have been reported under the designation of the "Cruveilhier-Baumgarten syndrome." Armstrong, Adams, Tragerman, and Townsend (1942) reviewed the relevant literature, reporting two new examples and defining the syndrome as "portal venous obstruction, generally with splenomegaly, visible (epigastric veins) and murmur and thrill indicating excessively prominent circulation in the umbilical region." A further example was reported by Miller (1945). In 23 cases reported by Armstrong and others, the large vein in the falciform ligament was observed at necropsy. The incidence of haematemesis in such patients is $38.4 \%$, and in $30.7 \%$ it is the cause of death (Table 1 ).

TABLE I

InCIDence of Haematemesis and Death from Haematemesis in Patients Suffering from the Cruveilhier-Baumgarten SYNDROME

\begin{tabular}{|c|c|c|c|}
\hline Author & $\begin{array}{l}\text { No. of } \\
\text { Cases }\end{array}$ & $\begin{array}{l}\text { No. with } \\
\text { Haemat- } \\
\text { emesis }\end{array}$ & $\begin{array}{l}\text { No. Dying } \\
\text { from Haemat- } \\
\text { emesis }\end{array}$ \\
\hline \begin{tabular}{lll} 
Armstrong et al. & \multicolumn{1}{c}{$(1942)$} \\
Miller (1945) & $\ldots$ & $\ldots$ \\
Present series & $\ldots$ & $\ldots$
\end{tabular} & $\begin{array}{r}23 \\
1 \\
2\end{array}$ & $\begin{array}{l}7 \\
1 \\
2\end{array}$ & $\begin{array}{l}6 \\
1 \\
1\end{array}$ \\
\hline Totals & 26 & $10(38.4 \%)$ & $8(30 \cdot 7 \%)$ \\
\hline
\end{tabular}

A comparable condition was reported by Learmonth (1949), who stated:

“. . occasionally a direct collateral from the splenic vein joins the left renal vein. In this particular specimen a large vein, of an internal diameter of $6 \mathrm{~mm}$., joined the upper border of the left renal vein. This is a natural portal-caval shunt, and it is as large as can usually be constructed by the surgeon. Its failure to prevent oesophageal bleeding in this patient makes one wonder if limited shunting is really an effective way of trying to reduce portal venous pressure."

Similar doubts as to the effectiveness of the surgical anastomosis of two veins in reducing greatly the portal venous pressure were expressed by Snell (1950).

The recorded results of artificial (i.e. surgical) portal-caval shunts shows that bleeding still occurs after a successful shunt although its severity and frequency are often much reduc:d, and that th: 
persistence of varices is demonstrable by radiography and oesophagoscopy. The effect of any adequate shunt, whether naturally achieved or surgically effected, must be but temporary, since the progressive nature of the cirrhotic lesion must promote continually increasing portal venous pressure and thereby neutralize the benefit of any such shunt. As the shunt gradually becomes inadequate the internal varices must become re-distended, thereby increasing the risk of bleeding. Eradication of the varix-bearing area of the gut, either alone or combined with a shunt operation, would appear to be a more logical mode of treatment than a shunt operation alone. Eradication might be effected by the injection of a sclerosing fluid or by surgical excision. The former procedure is unsatisfactory because it is applicable only to the oesophageal varices, whereas the gastric varices are the commoner source of bleeding and also because of the multiplicity of the juxta-cardiac varices. The results of such treatment, when alone employed, are very unsatisfactory (Moersch, 1947).

Resection of the lower 3 or $4 \mathrm{~cm}$. of the oesophagus together with a considerable portion of the stomach (Phemister and Humphreys, 1947; Sheline, Clark, Adams, and Phemister, 1951) removes most of the area containing the vulnerable varices and the varices in the remaining part of the oesophagus will thereby be severed from their direct connexions with the portal venous system via the left gastric vein. Furthermore, such a resection removes a large area of the gastric mucosa, and so reduces the amounts of $\mathrm{HCl}$ and pepsin which appear to be such important factors in the mechanism of erosion of the vulnerable varices. Resection is open to the objection that new vessels may grow across the suture line and thus re-connect the remaining oesophageal varices with the portal venous system. No direct eviderce on this point is, at present, available, but the formation in the operation scar ti sue of any very large vessels would appear to be unlikely. The preliminary results of this operation suggest that, even without a concomitant shunt, very satisfactory results are obtained (Sheline and others, 1951).

\section{SUMMARY}

The portal-caval anastomoses in and around the upper part of the stomach and the lower portion of the oesophagus and in the hepatic falciform ligament are described in three cases of portal venous obstruction due to hepatic cirrhosis.
The varices in and around the gastro-oesophage: region are divisible into two groups (connected by numerous intramuscular varices): (1) intern? varices, extremely numerous, thin-walled varicess in the lamina propria and the submucosa which bulge into the gut lumen, and (2) external variofs upon the outer surface of the stomach and oesg phagus close to the vagus nerves.

Two of the three cases described had large veibs in the falciform ligament, uniting the left branch of the portal vein to the epigastric veins. These intr: falciform veins are comparable in size to the artit ficially produced anastomoses constructed in the portal-caval shunt operations. Portal-caval angy stomoses are classified as "vulnerable" or "protected" according to their situation relative to the gut lumen and to their clinical potentialities. The vulnerable varices include the internal varices a ad form the source of bleeding in portal venows obstruction. The bearing of these facts upon the treatment of haematemesis due to portal venoưs obstruction is discussed.

My thanks are due to Dr. L. W. Cole for permissiên to publish the material from his patients, to Dr. A. Barrett and his colleagues for their care and troufe in removing the specimens for injection, and to Professofs H. A. Harris and A. J. E. Cave for constant advise and encouragement. The photographs are the work of Mr. J. A. F. Fozzard and the sections are that 要 Mr. J. F. Simpkin.

\section{REFERENCES}

Armstrong, E. L., Adams, W. L., Tragerman, L. J., and Townsemd, E. W. (1942). Ann. intern. Med., 16, 113.

Baronofsky, I., and Wangensteen, O. H. (1945). Proc. Soc. बू্ Biol., N.Y., 59, 234.

Beswick, T. S. L., and Butler, H. (1951). Brit. med. J., 2, 522.

Blakemore, A. H. (1948). Ann. Surg., 128, 825.

Blond, K., and Haler, D. (1950). The Liver. Porta Malorum. Bp 67-87. Bristol.

Burow, K. A. von (1838). Arch. Anat. Physiol., Berl., p. 44.

Butler, H. (1951). Thorax, 6, 276.

Fauvel (1858). Rec. Trav. Soc. méd. Obs. Paris, 1, 271. Quote foby Preble, 1900.

Frerichs, F. T. (1861). A Clinical Treatise on Diseases of the L $\overline{\overline{y G}}$. Trans. C. Murchison, vol. 2, p. 39. London.

Kegaries, D. L. (1934). Surg. Gynec. Obstet., 58, 46.

Learmonth, J. (1949). Proc. roy. Soc. Med., 42, 437. Learmonth, J. (1949). Proc. roy. Soc. Med., 42, 437.
Linton, R. R., Hardy, I. B., and Volwiler, W. (1948). Surg. Gypge.
Obstet., 87, 129.

McIndoe, A. H. (1928). Arch. Path., Chicago, 5, 23.

Miller, S. E. (1945). Ibid., 40, 405.

Moersch, H. J. Personal communication quoted by Phemister Humphreys, 1947. Phemister, D. B., and Humphreys, E. M. (1947). Ann. Surg.,

Portal, A. (1803). Cours d'Anatomie Médicale, vol. 4, p. 539 . Pads.

Preble, R. B. (1900). Amer. J. med. Sci., 119, 263.

Sappey, P. C. (1889). Traité d'Anatomie Descriptive, 4th ed., voț 4,

p. 310. Paris.
Sheline, G. E., Clark, D. E., Adams, w. E., and Phemister, D (1951). Surg. Clin. N. Amer., 31, 213.

Snell, A. M. (1950). Proc. Mayo Clin., $25,36$.

Walker, R. M. (1949). Practitioner, 162, 211.

Weinberg, T. (1949). Amer. J. clin. Path., 19, 554.

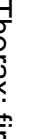

